\title{
Knowledge, attitude, and practices toward COVID-19 among the international travelers in Thailand
}

Suttiporn Prapaso ${ }^{1}$, Viravarn Luvira ${ }^{*^{*}}$ D, Saranath Lawpoolsri², Archin Songthap ${ }^{3}$, Watcharapong Piyaphanee ${ }^{1}$ Wiwat Chancharoenthana', Sant Muangnoicharoen ${ }^{1}$, Punnee Pitisuttithum ${ }^{1}$ and Pornthep Chanthavanich ${ }^{4}$

\begin{abstract}
Background: International travel is among the leading impactful factors of COVID-19 transmission; thus, adequate knowledge, good attitude and good preventive practices toward COVID-19 for international travelers are particularly essential for successful pandemic control.

Methods: A cross-sectional, questionnaire-based study was conducted to determine knowledge, attitude and practices (KAP) of international travelers (both Thai and non-Thai) and expatriates in Thailand. The data were collected at the Thai Travel Clinic, Bangkok, Thailand and via online platforms during May to October 2020. The independent T-test, Chi-square test and multiple regression analysis (MRA) were applied to determine factors influencing the KAP.
\end{abstract}

Results: Of 399 travelers, $46.6 \%$ were male, $72.1 \%$ had a Bachelor's degree or higher, and the mean age was $35.6 \pm$ 9.6 years. Due to unexpected travel restrictions and lock down, $77.9 \%$ of participants were Thai and the respective major purpose of travel was business/work. Travel cancellation/postponement was reported at $73.9 \%$. While sufficient knowledge ( $\geq 60 \%$ correct answers) was reported in $77.9 \%$ of participants, a low percentage of correct answers was found in the questions regarding disease transmission. The travelers reported a neutral attitude and an overall moderate concern regarding the COVID-19 situation. Adequate preventive practices were determined by the average practice score $3.54 \pm 0.38(0=$ never and $4=$ always $)$. The MRA revealed that the factors influencing good practices were travelers who: i) enrolled from outside the hospital (online platform); ii) received pretravel advice at hospital; iii) were female; iv) participated before the declaration of the end of the outbreak; v) were aged 40-49 years, and vi) visited friends and relatives.

Conclusions: The majority of travelers in this study had sufficient knowledge, a neutral attitude and adequate preventive practices toward COVID-19. The factors influencing good practices included pretravel advice, sex, age and the point in the timeline of the outbreak. In order to better control the COVID-19 pandemic situation, pretravel counselling and advice should be promoted as a means to improve knowledge, particularly in disease transmission, increase awareness and emphasize appropriate preventive measures toward COVID-19 among international travelers. Furthermore, preventive practices should be bolstered at all times regardless of the outbreak situation.

Keywords: Knowledge, Attitude, Practices, Coronavirus disease 2019, Travelers

\footnotetext{
* Correspondence: viravarn.luv@mahidol.ac.th

'Department of Clinical Tropical Medicine, Faculty of Tropical Medicine, Mahidol University, Bangkok, Thailand

Full list of author information is available at the end of the article
}

(c) The Author(s). 2021 Open Access This article is licensed under a Creative Commons Attribution 4.0 International License, which permits use, sharing, adaptation, distribution and reproduction in any medium or format, as long as you give appropriate credit to the original author(s) and the source, provide a link to the Creative Commons licence, and indicate if changes were made. The images or other third party material in this article are included in the article's Creative Commons licence, unless indicated otherwise in a credit line to the material. If material is not included in the article's Creative Commons licence and your intended use is not permitted by statutory regulation or exceeds the permitted use, you will need to obtain permission directly from the copyright holder. To view a copy of this licence, visit http://creativecommons.org/licenses/by/4.0/ The Creative Commons Public Domain Dedication waiver (http://creativecommons.org/publicdomain/zero/1.0/) applies to the data made available in this article, unless otherwise stated in a credit line to the data. 


\section{Background}

In mid-December 2019, Coronavirus disease 2019 (COVID-19), a new emerging disease from "severe acute respiratory syndrome coronavirus 2 (SARS-CoV-2)", was identified in Wuhan city, Hubei province, China. Since then, the disease has spread globally and wreaked havoc on all communities in its path, leading to a global pandemic within three months. Despite extensive attempts to control the outbreak, the number of COVID-19 cases increased exponentially in more than 100 countries and has accounted for millions of deaths worldwide.

Before the COVID-19 era, international travel was immensely popular, with a yearly continuous increase in figures. However, international travel is among the most significant contributing factors toward COVID-19 spreading during the pandemics infancy. Consequently, travel-related control protocols, including border closures, travel restrictions, vigorous exit and entry screening and traveler quarantine, have been implemented in tandem with policies to permit only essential travel in several countries as a measure to contain the pandemic. Despite the Thai Department of Disease Control having declared the response protocol against COVID-19 on January 4, 2020, the first confirmed COVID-19 case outside China was reported in Thailand a week later. She was a 61-yearold Chinese woman traveling from Wuhan as an international tourist [1]. A taxi driver who made contact with the sick Chinese traveler, was later diagnosed and confirmed as the first local transmission COVID-19 case [2]. An accelerated increase in cases prompted the Thai government to declare a state of emergency, impose a national lockdown, suspend all international flights and establish a quarantine system for international travelers upon arrival at the end of March 2020 [3].

COVID-19 is an imminent threat toward global health while international travel is a factor that promotes disease transmission. Thus, traveler behavior plays a significant role in disease control and mitigation. Inappropriate awareness regarding COVID-19 may have some ramifications in term of a detrimental pandemic situation while appropriate knowledge regarding COVID-19 may assist with pandemic prevention. Since travel restrictions and quarantine measures may not be practical long-term as COVID-19 solutions, enhancing traveler knowledge and improving attitude which lead to effective preventive practices against the disease should be incorporated. Although studies have been conducted on knowledge, attitude, and practices (KAP) regarding COVID-19 in various populations, including health care workers in China, university students in Japan, and border communities in Northern Thailand [4-17], data for the traveler population have yet to be explored. Hence, this study aimed to investigate the KAP toward COVID-19 among international travelers in Thailand and identify the factors influencing the level of knowledge and preventive behaviors throughout the pandemic. As expatriates are collectively travelers, the KAP of expatriates living in Thailand were also studied.

\section{Materials and methods \\ Study design and population}

A cross-sectional, questionnaire-based study was conducted. The study population included international travelers and expatriates in Thailand. All participants were older than 18 years with sufficient understanding of the language within the questionnaire (English or Thai) and were willing to participate in the study. Notably, both Thai and non-Thai participants who had traveled internationally within three months before the interview or planned to travel within one month after answering the questionnaire were recruited.

\section{Study questionnaire}

A bilingual (Thai and English) questionnaire consisted of four parts: i) demographic data and general information related to travel; ii) knowledge; iii) attitude and iv) practices. The knowledge was assessed using 12 multiple-choice questions (four transmission, two signs and symptoms, one diagnostic and five COVID-19 prevention). The attitude part consisted of 16 "5-level Likert scale" questions, eliciting attitude toward COVID-19 transmission, complications, treatments, prevention, and control measures. The participants were also requested to provide a score regarding their concern over the COVID-19 situation, ranging from 0 to 10 (none to maximum concern). The practice part contained ten questions, which inquired as to the frequency of the practices in COVID-19 preventive methods. The reliability of the questionnaire was evaluated among 44 respondents who were not included in the study. Moreover, five experts also verified the questionnaire content validity.

\section{Data collection}

All eligible travelers at the Thai Travel Clinic, the Hospital for Tropical Diseases, Bangkok, were approached, invited, informed and consented to participate in the study. This clinic is the biggest travel clinic in Thailand and is a part of GeoSentinel surveillance sites, which was established in 2005 to provide comprehensive health care for travelers and offer a residency training program in Travel medicine.

In addition to data collection at Thai Travel Clinic, a link to the online questionnaire was also distributed via social media platforms (Facebook and LINE) to recruit eligible participants outside the hospital. This participant pool included limited access to online application groups of expatriates, soldiers commissioned for overseas 
deployment, and state quarantines as well as the Thai Travel Clinic Facebook page.

\section{Study timeline}

The timeline of the study and Thailand's COVID-19 situation during the study period is displayed in Fig. 1. The first wave of the COVID-19 outbreak began in early March 2020 and subsequently reached peak levels by the end of the same month at which point a national lockdown was enforced. This investigative study was conceived in mid-March, had completed the questionnaire testing and validation phase by early April, and recruited participants from May 21, onwards at which point the local community outbreak was controlled and very few COVID-19 cases were prevalent. In August 2020, nonThai international travelers were allowed to enter Thailand.

Data collection time was divided by the end of the first community COVID-19 outbreak (declared on July 8) into two periods, as seen in Fig. 1. Data collection was completed in October before the second wave of the outbreak began, in December 2020.

\section{Statistical analysis}

With no prior published data associated to this study, a sample size of 385 was calculated based on the assumption that $50 \%$ of participants have a sufficient knowledge score regarding COVID-19 with a 95\% confidence interval. Data were analyzed using SPSS statistics software version 23. Descriptive statistics, an independent T-test and the Chi-square test were used. The multivariable logistic regression was used to determine the association between potential factors and level of knowledge. A sufficient knowledge was defined as getting the correct answer in $\geq 60 \%$ ( $\geq 8$ from 12 questions). The attitude was assessed using a 5-level Likert scale with answers ranging from 1 (strongly disagree) to 5 (strongly agree). The practices were given a score ranging from 4 (always) to 1 (never). A $p$-value below 0.05 was regarded as statistically significant.

\section{Results}

The total number of participating travelers in the study was 411. Data were then rechecked and validated; 12 travelers were excluded because they had traveled back to Thailand for $>90$ days. Therefore, a total of 399 participants were included for data analysis. The site of data collection is displayed in Additional file 1.

\section{General characteristics of participants and their travels} Of the 399 participants, 224 (56.1\%) participants were enrolled during the first period of the study (May-June) and 149 (37.3\%) participants were enrolled at the Thai Travel Clinic. The demographic data of the participants are displayed in Table 1 . The most common purpose of travel was business/work. Of note, $40 \%$ of travelers had experienced the test for COVID-19 and two of them had positive results. In addition, $90 \%$ of participants sought pretravel advice, and $54.4 \%$ sought a pretravel consultation at hospitals/clinics.

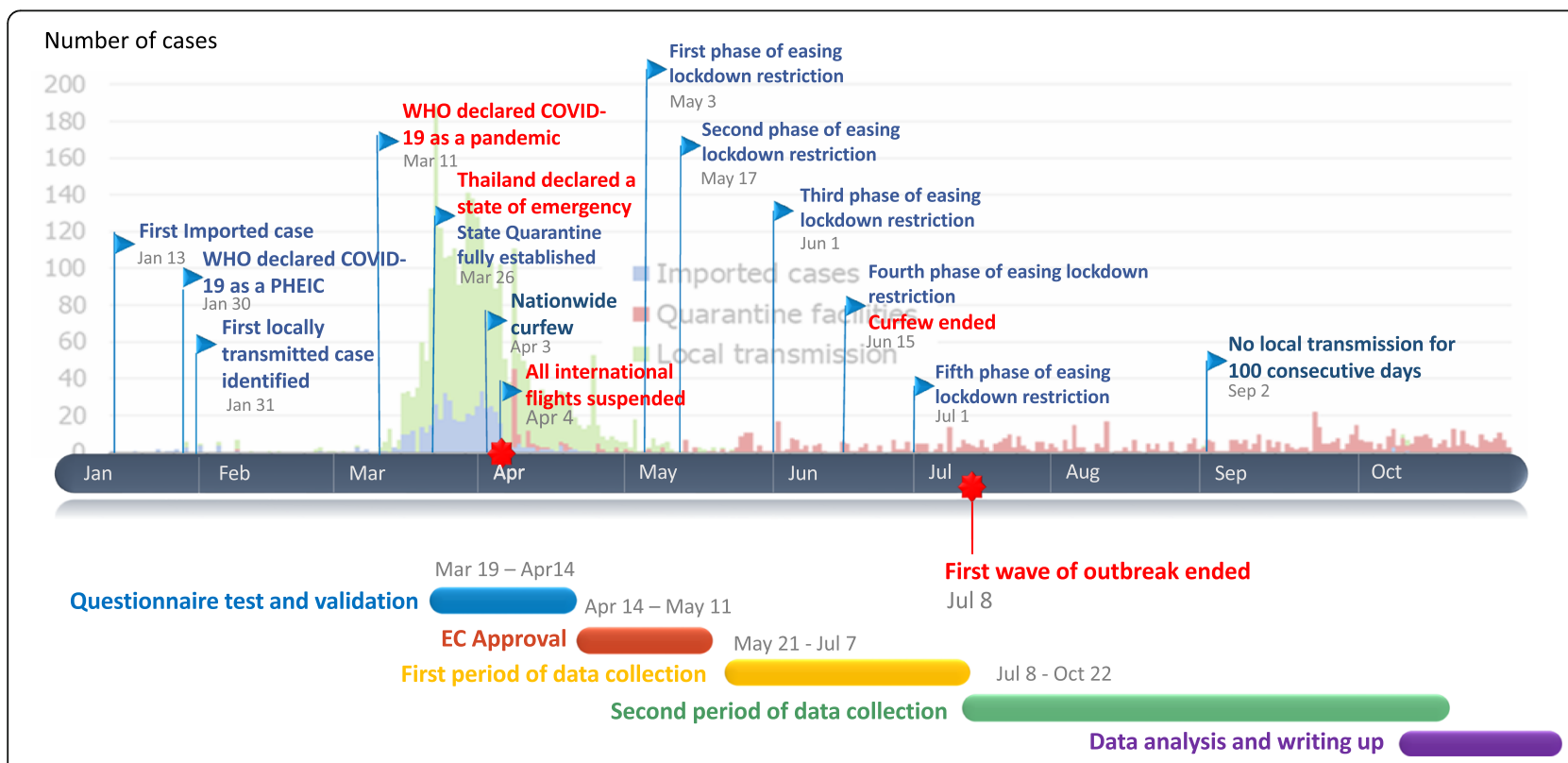

Fig. 1 Timeline of the study and Thailand's COVID-19 situation. The number of COVID-19 cases is plotted in the timeline bar graph and includes Thailand's COVID-19 situation whereby important events are described. The study timeline is also exhibited below 
Table 1 Demographic data of participants $(N=399)$

\begin{tabular}{|c|c|}
\hline Parameters & N (\%) \\
\hline \multicolumn{2}{|l|}{ Date of data collection } \\
\hline May-June & $224(56.1 \%)$ \\
\hline July - Oct & $175(43.9 \%)$ \\
\hline \multicolumn{2}{|l|}{ Site of data collection } \\
\hline Thai Travel Clinic (inside hospital) & $149(37.3 \%)$ \\
\hline Outside hospital & $250(62.7 \%)$ \\
\hline Age $($ mean $\pm S D)$ & $35.6 \pm 9.6$ \\
\hline $18-29$ & $117(29.3 \%)$ \\
\hline $30-39$ & $169(42.4 \%)$ \\
\hline $40-49$ & $76(19 \%)$ \\
\hline 50 or above & $37(9.3 \%)$ \\
\hline Gender: Male & $186(46.6 \%)$ \\
\hline \multicolumn{2}{|l|}{ Type of traveler } \\
\hline Thai & $331(77.9 \%)$ \\
\hline Non-Thai & $88(22.1 \%)$ \\
\hline \multicolumn{2}{|l|}{ Occupation } \\
\hline Healthcare & $31(7.8 \%)$ \\
\hline Non-healthcare & $256(64.1 \%)$ \\
\hline Unemployed & $112(28.1 \%)$ \\
\hline \multicolumn{2}{|l|}{ Purpose of travel } \\
\hline Leisure & $81(20.3 \%)$ \\
\hline Business/work & $175(43.9 \%)$ \\
\hline Visiting friends or relatives & $46(11.5 \%)$ \\
\hline Study & $60(15 \%)$ \\
\hline Other & $37(9.3 \%)$ \\
\hline \multicolumn{2}{|l|}{ Education } \\
\hline Secondary school or lower & $111(27.9 \%)$ \\
\hline Bachelor's or higher & $288(72.1 \%)$ \\
\hline \multicolumn{2}{|l|}{ Influenza vaccination in past 1 year } \\
\hline Yes & $172(43.1 \%)$ \\
\hline \multicolumn{2}{|l|}{ Previous COVID-19 testing } \\
\hline Yes & $162(40.6 \%)$ \\
\hline \multicolumn{2}{|c|}{ Seeking pretravel advice/recommendation } \\
\hline Yes & $361(90.5 \%)$ \\
\hline \multicolumn{2}{|l|}{ Pretravel consultation at hospitals/clinics } \\
\hline Yes & $217(54.4 \%)$ \\
\hline
\end{tabular}

Major sources of information about COVID-19 were social media (86.5\%) and TV/radio (65.7\%). Approximately three-quarter of participants reported that the COVID-19 pandemic had greatly affected their travel plans and resulted in trip cancellations or postponements (Table 2). The most common reason accounting for half of the cancellation and/or postponement was the travel restrictions from departure airports or the destination countries.
Table 2 Effects of COVID-19 on travel plan

\begin{tabular}{ll}
\hline Questions & N (\%) \\
\hline Does COVID-19 affect your travel plan? & $293(73.4 \%)$ \\
A lot & $75(18.8 \%)$ \\
Some & $23(5.8 \%)$ \\
A little & $8(2.0 \%)$ \\
None & \\
How does COVID-19 affect your trip? & $101(25.3 \%)$ \\
Trip cancellation & $196(48.6 \%)$ \\
Trip postponement & $64(16.0 \%)$ \\
Minor plan change & $13(3.3 \%)$ \\
No effect & $27(6.8 \%)$ \\
No trip planned & $211(52.9 \%)$ \\
The main reason for trip cancellation or postponement? & $\left({ }^{*}\right)$ \\
Travel restriction in home country & $194(48.6 \%)$ \\
Travel restriction at destination country & $65(16.3 \%)$ \\
My employer did not allow it & $121(30.3 \%)$ \\
I was worried about the situation & $33(8.3 \%)$ \\
I did not cancel or postpone my trip & $16(4.0 \%)$ \\
I did not have any trip planned & $16(4.0 \%)$ \\
I had to work from home &
\end{tabular}

*multiple answers

\section{Knowledge on COVID-19}

Twelve knowledge questions and the corresponding number of participants with correct answers are shown in Table 3. The knowledge score ranged from 4 to 12 , and the mean was $8.64 \pm 1.58$. The mean knowledge score was significantly higher among travelers whose data were collected outside the hospital $(8.79 \pm 1.55$ vs $8.39 \pm 1.60, p$-value $<0.001)$, among those who were Thai $(8.73 \pm 1.55$ vs $8.34 \pm 1.65, p$-value 0.041$)$, had a Bachelor's or higher education level $(8.89 \pm 1.47$ vs $8.02 \pm 1.67, p$-value <0.001), had been tested for COVID-19 earlier $(8.84 \pm 1.41$ vs $8.51 \pm 1.67, p$-value $0.035)$, or had a history of influenza vaccination in the past year $(8.95 \pm 1.45$ vs $8.41 \pm 1.64, p$-value $<0.001)$. The mean knowledge score was also significantly higher in the group whose data were collected in the first period of the study $(8.79 \pm 1.57$ vs $8.46 \pm 1.58, p$-value 0.042) (See Additional file 2).

Sufficient knowledge regarding COVID-19 (scored $\geq 60 \%$ ) was reported in $77.9 \%$ of participants. The factors that were associated with sufficient knowledge were further determined using the logistic regression analysis. (Table 4) The covariates with $p$-value $<0.1$ in univariate models were included in the multivariable analysis. The factors independently associated with a sufficient knowledge score were type of travelers (Thai) and education level (Bachelor's degree or above). 
Table 3 Percentages of participants with correct answer

\begin{tabular}{|c|c|}
\hline Questions & $\mathrm{N}(\%)$ - correct answer \\
\hline \multicolumn{2}{|l|}{ 1. Which of the following is not a route of Coronavirus spread? } \\
\hline Mosquito & $317(79.4 \%)$ \\
\hline \multicolumn{2}{|l|}{ 2. What are the common symptoms of COVID-19? } \\
\hline Fever, cough, and difficulty breathing & $379(95 \%)$ \\
\hline \multicolumn{2}{|c|}{ 3. Which of the following is the most reliable way to test for COVID-19 infection during the first week of illness? } \\
\hline Testing for genetic material from nasopharyngeal swab & $354(88.7 \%)$ \\
\hline \multicolumn{2}{|l|}{ 4. Which group is at the lowest risk of developing severe disease? } \\
\hline Children & $144(36.1 \%)$ \\
\hline \multicolumn{2}{|c|}{ 5. In order to prevent the spread of COVID-19, if you have only one mask, who should get this mask? } \\
\hline Patient with cough & $322(80.7 \%)$ \\
\hline \multicolumn{2}{|l|}{ 6. Which one is the most appropriate mask for COVID-19 patient? } \\
\hline Surgical mask & $186(46.6 \%)$ \\
\hline \multicolumn{2}{|l|}{ 7. How can you prevent COVID-19 infection? } \\
\hline Washing hands with alcohol & $388(97.2 \%)$ \\
\hline \multicolumn{2}{|l|}{ 8. Which of the following is the least useful preventive measure? } \\
\hline Wearing gloves & $339(85 \%)$ \\
\hline \multicolumn{2}{|c|}{$\begin{array}{l}\text { 9. After having been in close contact with a confirmed case of COVID-19, how long should you have a self-quarantine if you do not have any } \\
\text { symptoms? }\end{array}$} \\
\hline 14 days & $378(94.7 \%)$ \\
\hline \multicolumn{2}{|c|}{ 10. If the red dot is a patient infected with COVID-19, which passenger is at the lowest risk of getting infected? } \\
\hline A (3 rows from the index case) & $85(21.3 \%)$ \\
\hline \multicolumn{2}{|l|}{ 11. How long should you wash your hands for to reduce the spreads of coronavirus? } \\
\hline$\geq 20 \mathrm{~s}$ & $374(93.7 \%)$ \\
\hline \multicolumn{2}{|l|}{ 12. Who would be identified as a close contact of COVID-19 patient? } \\
\hline People who share a dining table with the patient but use serving spoons & $183(45.9 \%)$ \\
\hline
\end{tabular}

\section{Attitude toward COVID-19}

The attitude toward COVID-19 is displayed in Fig. 2. Nearly $80 \%$ of participants had agreed that COVID-19 was easier to spread than influenza and international travel should be discouraged throughout the outbreak. Approximately $60 \%$ of participants agreed that international travel posed greater risk than domestic travel. Over $80 \%$ of participants consider it is necessary for travelers from COVID-19 active countries to quarantine and mask-wearing to be mandatory in public. Seventy percent of participants agreed that their respective home country's healthcare facilities were easily accessible in an event they developed abnormal symptoms. However, only $41 \%$ agreed that easily accessible healthcare facilities were available if abnormal symptoms arose at their destination countries.

The mean concern score over the COVID-19 situation was $6.09 \pm 2.32$ (maximum concern $=10$ ). There were no significant differences in the mean score between the two data collection periods ( $p$-value 0.703 ).

\section{Practices}

Although the overall mean practice score was high, a wide variation in the practice rate of each preventive measure was reported. The practices for reducing COVID-19 transmission were assessed by their frequency within several preventive parameters, ranging from 4 (always) to 1 (never). The mean practice score was $3.54 \pm 0.38$. The rate of 'always practices' by item ranged from 33.8-96.5\% (Fig. 3). Almost all participants reported regular practices of basic preventive procedures against COVID-19. The rate of 'always practices' was high in the categories of wearing a mask when going to public places $(96.5 \%)$, hand washing $(88.5 \%)$ and avoiding contact with sick people $(86 \%)$. However, only half of the participants reported good practices in the categories of avoiding going to public areas/using public transportation during rush hour, cleaning high touch surfaces every day, and checking body temperature when they feel unwell.

To determine factors influencing practices regarding COVID-19 prevention, the stepwise multiple regression 
Table 4 Factors associated with sufficient knowledge

\begin{tabular}{|c|c|c|c|c|}
\hline & \multicolumn{2}{|l|}{ Knowledge } & \multirow[b]{2}{*}{$\begin{array}{l}\text { OR } \\
(95 \% \mathrm{Cl})\end{array}$} & \multirow[b]{2}{*}{$\begin{array}{l}\text { Adjusted OR } \\
(95 \% \mathrm{Cl})\end{array}$} \\
\hline & $\begin{array}{l}\text { Sufficient* } \\
N(\%)\end{array}$ & $\begin{array}{l}\text { Insufficient } \\
\mathrm{N}(\%)\end{array}$ & & \\
\hline \multicolumn{5}{|l|}{ Site of data collection } \\
\hline Thai Travel Clinic & $107(71.8 \%)$ & $42(28.2 \%)$ & 1 & 1 \\
\hline Non-hospital areas & $204(81.6 \%)$ & $46(18.4 \%)$ & $1.74(1.08-2.81)$ & $1 . .21(0.69-2.10)$ \\
\hline \multicolumn{5}{|l|}{ Traveler } \\
\hline Thai & $216(69.5 \%)$ & $95(30.5 \%)$ & 1 & 1 \\
\hline Non-Thai & $15(51.7 \%)$ & $14(48.3 \%)$ & $0.38(0.17-0.84)$ & $0.51(0.21-1.23)$ \\
\hline Expatriate & $34(57.6 \%)$ & $25(42.4 \%)$ & $0.48(0.26-0.89)$ & $0.45(0.23-0.89)$ \\
\hline \multicolumn{5}{|l|}{ Education } \\
\hline Secondary or lower & $56(68.5 \%)$ & $35(37.5 \%)$ & 1 & 1 \\
\hline Bachelor's or higher & $235(81.6 \%)$ & $53(18.4 \%)$ & $2.04(1.24-3.36)$ & $2.16(1.28-3.65)$ \\
\hline \multicolumn{5}{|c|}{ Influenza vaccination in the past 1 year } \\
\hline No & $129(56.8 \%)$ & $93(43.2 \%)$ & 1 & 1 \\
\hline Yes & $136(79.1 \%)$ & $36(20.9 \%)$ & $1.85(1.12-3.05)$ & $1.50(0.88-2.55)$ \\
\hline \multicolumn{5}{|c|}{ Previous COVID-19 testing } \\
\hline No & $144(60.8 \%)$ & $93(39.2 \%)$ & 1 & 1 \\
\hline Yes & 121 (74.7\%) & 41 (25.3\%) & $1.62(0.98-2.68)$ & $1.17(0.66-2.07)$ \\
\hline
\end{tabular}

analysis (MRA) was employed. With respect to sociodemographic characteristics, the independent influencing factors for practices in COVID-19 prevention were site of data collection, pretravel advice at hospital, gender, period of data collection, age, and purpose of travel. (Table 5) The results revealed that mean practice score tended to be higher in participants who completed the questionnaire from outside the hospital (Beta $=0.195)$, participants who sought pretravel advice (compared with those who did not $)($ Beta $=0.168)$ and females (Beta $=$ 0.154). In contrast, participants in the second period of data collection tended to have lower mean practice score (Beta $=-0.153)$. Participants aged $40-49$ years had higher mean practice score compared to those who were younger or older (Beta $=0.143$ ). Lastly, participants who visited friends and relatives were more likely to have higher mean practice score than other travel purposes $($ Beta $=0.107)$.

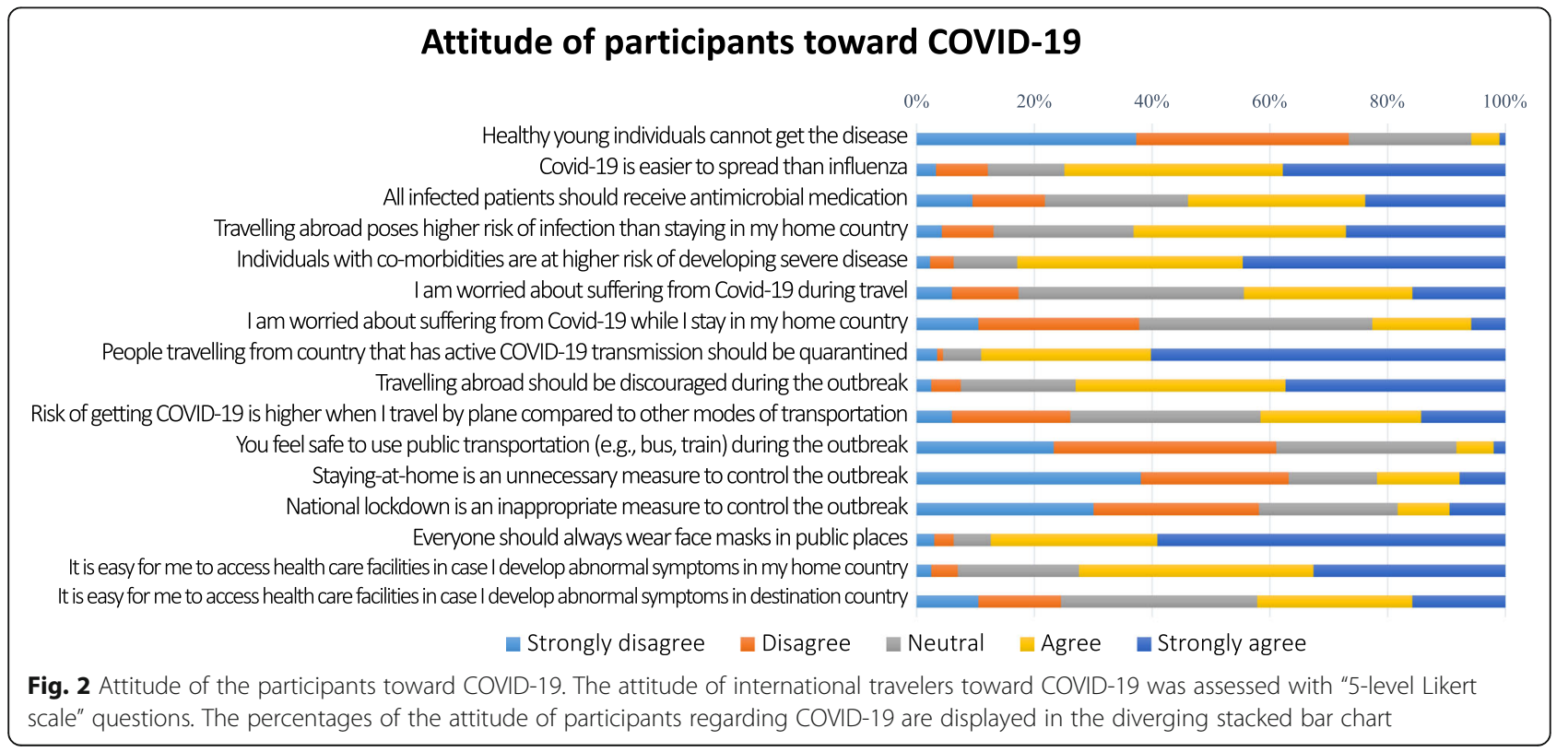


Practices of participants toward COVID-19

Wear masks when you go to public places even when you are healthy Hand washing with soap and water, or alcohol-base hand rub Avoid going to public places (e.g., department store) Avoid using public transportation during rush hours Avoid contact with sick people Try to stock up food and essential household items during the outbreak Clean high touch surfaces everyday (eg. mobile phone, doorknob etc.) Follow the updated knowledge and recommendations regarding Covid-19 If you feel unwell, you will check your body temperature with thermometer Avoid sharing fork and spoon during eating

Always Sometimes $\square$ Rarely $\square$ Never

Fig. 3 Practices of the participants toward COVID-19. The percentages of participants' practices of ten preventive measures toward COVID-19 are plotted in the stacked bar graph

The differences in the practices of participant groups were then evaluated by item using the Chi-square test, and the percentage of participants who regularly (always) practice preventive measures were compared with those who do not regularly (sometime/rarely/never) practice (Table 6). Overall, the results showed a higher trend of 'always practices' in the first period than the second period of data collection. Most participants always wore a mask when going to public places, and there were no differences between different groups except Thai and non-Thai travelers $(98.1 \%$ vs $90.9 \%, p$-value 0.001$)$. The hand hygiene practice was significantly higher in females and in the first period of data collection. Furthermore, the practice of cleaning high touch surfaces everyday was significantly more common among females, lower education group, Thai travelers, and among participants in the first period of data collection.

\section{Discussion}

With international travel as a major contributing factor toward COVID-19 transmission, appropriate disease preventive behaviors within traveler groups is crucial for

Table 5 Factors influencing practice on COVID-19 (Stepwise MRA)

\begin{tabular}{llll}
\hline Independent variables & b & Beta & $\boldsymbol{p}$-value \\
\hline Site of data collection (outside hospital) & 0.152 & 0.195 & $<0.001$ \\
Pretravel advice at hospital (Yes) & 0.127 & 0.168 & $<0.001$ \\
Gender (female) & 0.116 & 0.154 & 0.001 \\
Period of data collection (second) & -0.116 & -0.153 & 0.003 \\
Age (40-49years) & 0.138 & 0.143 & 0.002 \\
Purpose of travel (VFR) & 0.126 & 0.107 & 0.022 \\
Constant & 2.903 & & $<0.001$ \\
\hline
\end{tabular}

$\mathrm{R}=0.415 \mathrm{R}^{2}=0.173 \mathrm{~F}=13.621 p$-value $<0.001$

$\mathrm{VFR}=$ visiting friends and relatives pandemic control. For this reason, we investigated traveler knowledge and attitudes toward COVID-19 in addition to the prevalence of preventive protocol practices regarding COVID-19 among travelers and expatriates in Thailand. Although the KAP relating to COVID19 had been assessed in various populations [4-14, 1618], our original study pioneers elicited COVID-19 KAP data among the travelers. However, the unexpected lockdown and travel restrictions may have had an effect on study populations. Of note, most of the participants were Thai, aged 18-39, non-healthcare workers, had a high level of education and traveled for essential reasons (only $20 \%$ for leisure).

In terms of COVID-19 knowledge, the study revealed a high percentage of participants with good knowledge which was similar to those reported in several studies [48]. However, our findings were different from a previous KAP study in the border population of Northern Thailand at the very beginning of the outbreak which found that $73 \%$ of participants had poor knowledge [9]. The difference in results could be explained by both the baseline characteristics of participants and the period of the study. The factors that were associated with a sufficient knowledge score were: i) a higher education level (Bachelor's or above) which was consistent other studies [6, 9, 11-14] and ii) the nationality, possibly due to too few non-Thai travelers in our study. Comparable with the other KAP studies $[4,8,10,11]$, social media was the major source of knowledge concerning COVID-19. Therefore, improving reliability and maintaining up-to-date COVID-19 information on social media would contribute to better traveler knowledge. Interestingly, participants had relatively lower percentages of correct answers in questions pertinent to transmission when compared to symptoms and signs/diagnosis and prevention. This result indicates an opportunity to improve education toward COVID-19 transmission. 
Table 6 The difference between participant groups and practices of COVID-19 measured by each item (Chi-square test)

\begin{tabular}{|c|c|c|c|c|c|c|c|c|c|c|c|c|c|c|c|}
\hline & \multicolumn{3}{|c|}{ Data collection } & \multicolumn{3}{|c|}{ Gender } & \multicolumn{3}{|c|}{ Education } & \multicolumn{3}{|c|}{ Type of travellers } & \multicolumn{3}{|c|}{ Level of knowledge } \\
\hline & $\begin{array}{l}\text { May- } \\
\text { Jun } \\
(N=224)\end{array}$ & $\begin{array}{l}\text { Jul - Oct } \\
(\mathrm{N}=175)\end{array}$ & P-value & $\begin{array}{c}\text { Male } \\
(\mathrm{N}=186)\end{array}$ & $\begin{array}{l}\text { Female } \\
(\mathrm{N}=213)\end{array}$ & P-value & $\begin{array}{c}\text { Seconda } \\
\text { ry/ } \\
\text { lower } \\
(\mathrm{N}=111) \\
\end{array}$ & $\begin{array}{c}\text { Bachelo } \\
r / \\
\text { higher } \\
(\mathrm{N}=288) \\
\end{array}$ & P-value & $\begin{array}{l}\text { Thai } \\
(\mathrm{N}=331)\end{array}$ & $\begin{array}{l}\text { Non- } \\
\text { Thai } \\
(\mathrm{N}=88)\end{array}$ & P-value & $\begin{array}{c}\text { Sufficien } \\
t \\
(N=311)\end{array}$ & $\begin{array}{c}\text { Insuffici } \\
\text { ent } \\
(\mathrm{N}=88)\end{array}$ & P-value \\
\hline $\begin{array}{l}\text { 1. Wear masks when you go to } \\
\text { public places even when you are } \\
\text { healthy }\end{array}$ & $\begin{array}{c}215 \\
(96.0 \%)\end{array}$ & \begin{tabular}{|l}
170 \\
$(97.1 \%)$
\end{tabular} & 0.532 & $\begin{array}{c}180 \\
(96.8 \%)\end{array}$ & $\begin{array}{c}205 \\
(96.2 \%)\end{array}$ & 0.774 & $\begin{array}{l}108 \\
(97.3 \%)\end{array}$ & $\begin{array}{l}277 \\
(96.2 \%)\end{array}$ & 0.587 & $\begin{array}{l}305 \\
(98.1)\end{array}$ & $\begin{array}{c}80 \\
(90.9)\end{array}$ & 0.001 & $\begin{array}{c}302 \\
(97.1 \%)\end{array}$ & $\begin{array}{c}83 \\
(94.3 \%)\end{array}$ & 0.210 \\
\hline $\begin{array}{l}\text { 2. Hand washing with soap and } \\
\text { water, or alcohol-base hand rub }\end{array}$ & $\begin{array}{c}209 \\
(93.3 \%)\end{array}$ & $\begin{array}{c}144 \\
(82.3 \%)\end{array}$ & 0.001 & $\begin{array}{c}156 \\
(83.9 \%)\end{array}$ & $\begin{array}{c}197 \\
(92.5 \%)\end{array}$ & 0.007 & $\begin{array}{c}98 \\
(88.3 \%)\end{array}$ & $\begin{array}{c}255 \\
(88.5 \%)\end{array}$ & 0.943 & $\begin{array}{c}271 \\
(87.1)\end{array}$ & $\begin{array}{c}82 \\
(93.2)\end{array}$ & 0.117 & $\begin{array}{c}274 \\
(88.1 \%)\end{array}$ & $\begin{array}{c}79 \\
(89.8 \%)\end{array}$ & 0.665 \\
\hline $\begin{array}{l}\text { 3.Avoid going to public places (e.g. } \\
\text { department store) }\end{array}$ & $\begin{array}{c}138 \\
(61.5 \%) \\
\end{array}$ & $\begin{array}{c}61 \\
(34.9 \%)\end{array}$ & $<0.001$ & $\begin{array}{c}80 \\
(43.0 \%) \\
\end{array}$ & $\begin{array}{c}119 \\
(55.9 \%)\end{array}$ & 0.010 & $\begin{array}{c}53 \\
(47.7 \%) \\
\end{array}$ & $\begin{array}{c}146 \\
(50.7 \%) \\
\end{array}$ & 0.598 & $\begin{array}{c}165 \\
(53.1 \%)\end{array}$ & $\begin{array}{c}34 \\
(38.6 \%) \\
\end{array}$ & 0.017 & $\begin{array}{c}158 \\
(50.8 \%)\end{array}$ & $\begin{array}{c}41 \\
(46.6 \%)\end{array}$ & 0.485 \\
\hline $\begin{array}{l}\text { 4.Avoid using public transportation } \\
\text { during rush hours }\end{array}$ & $\begin{array}{c}135 \\
(60.3 \%)\end{array}$ & $\begin{array}{c}60 \\
(34.3 \%)\end{array}$ & $<0.001$ & $\begin{array}{c}88 \\
(47.3 \%)\end{array}$ & $\begin{array}{c}107 \\
(50.2 \%)\end{array}$ & 0.560 & $\begin{array}{c}45 \\
(40.5 \%)\end{array}$ & $\begin{array}{c}150 \\
(52.1 \%)\end{array}$ & 0.039 & $\begin{array}{c}153 \\
(49.2 \%)\end{array}$ & $\begin{array}{c}42 \\
(47.7 \%)\end{array}$ & 0.808 & $\begin{array}{c}152 \\
(48.9 \%)\end{array}$ & $\begin{array}{c}43 \\
(48.9 \%)\end{array}$ & 0.999 \\
\hline 5.Avoid contact with sick people & $\begin{array}{c}199 \\
(88.8 \%)\end{array}$ & $\begin{array}{c}144 \\
(82.3 \%)\end{array}$ & 0.061 & $\begin{array}{c}157 \\
(84.4 \%)\end{array}$ & $\begin{array}{c}186 \\
(87.3 \%)\end{array}$ & 0.403 & $\begin{array}{c}89 \\
(80.2 \%) \\
\end{array}$ & $\begin{array}{c}254 \\
(88.2 \%) \\
\end{array}$ & 0.039 & $\begin{array}{c}274 \\
(88.1 \%)\end{array}$ & $\begin{array}{c}69 \\
(78.4 \%)\end{array}$ & 0.021 & $\begin{array}{c}274 \\
(88.1 \%) \\
\end{array}$ & $\begin{array}{c}69 \\
(78.4 \%) \\
\end{array}$ & 0.021 \\
\hline $\begin{array}{l}\text { 6. Try to stock up food and essential } \\
\text { household items during the } \\
\text { outbreak just in case of emergency }\end{array}$ & $\begin{array}{c}87 \\
(38.8 \%)\end{array}$ & $\begin{array}{c}48 \\
(27,4 \%)\end{array}$ & 0.017 & $\begin{array}{c}46 \\
(24.7 \%)\end{array}$ & $\begin{array}{c}89 \\
(41.8 \%)\end{array}$ & $<0.001$ & $\begin{array}{c}45 \\
(40.5 \%)\end{array}$ & $\begin{array}{c}90 \\
(31.3 \%)\end{array}$ & 0.079 & $\begin{array}{c}106 \\
(34.1 \%)\end{array}$ & $\begin{array}{c}29 \\
(33.0 \%)\end{array}$ & 0.843 & $\begin{array}{c}96 \\
(30.9 \%)\end{array}$ & $\begin{array}{c}39 \\
(44.3 \%)\end{array}$ & 0.019 \\
\hline $\begin{array}{l}\text { 7.Clean high touch surfaces } \\
\text { everyday (eg. mobile phone, } \\
\text { doorknob etc.) }\end{array}$ & $\begin{array}{c}133 \\
(59.4 \%)\end{array}$ & $\begin{array}{c}84 \\
(48.0 \%)\end{array}$ & 0.024 & $\begin{array}{c}83 \\
(44.6 \%)\end{array}$ & $\begin{array}{c}134 \\
(62.9 \%)\end{array}$ & $<0.001$ & $\begin{array}{c}72 \\
(64.9 \%)\end{array}$ & $\begin{array}{c}145 \\
(50.3 \%)\end{array}$ & 0.009 & $\begin{array}{c}180 \\
(57.9 \%)\end{array}$ & $\begin{array}{c}37 \\
(42.0 \%)\end{array}$ & 0.008 & $\begin{array}{c}163 \\
(52.4 \%)\end{array}$ & $\begin{array}{c}54 \\
(61.4 \%)\end{array}$ & 0.137 \\
\hline $\begin{array}{l}\text { 8. Follow the updated knowledge } \\
\text { and recommendations regarding } \\
\text { Covid-19 }\end{array}$ & $\begin{array}{c}166 \\
(74.1 \%)\end{array}$ & $\begin{array}{c}135 \\
(77.1 \%)\end{array}$ & 0.485 & $\begin{array}{c}131 \\
(70.4 \%)\end{array}$ & $\begin{array}{c}170 \\
(79.8 \%)\end{array}$ & 0.030 & $\begin{array}{c}88 \\
(79.3 \%)\end{array}$ & $\begin{array}{c}213 \\
(74.0 \%)\end{array}$ & 0.269 & $\begin{array}{c}245 \\
(78.8 \%)\end{array}$ & $\begin{array}{c}56 \\
(63.6 \%)\end{array}$ & 0.004 & $\begin{array}{c}233 \\
(74.9 \%)\end{array}$ & $\begin{array}{c}68 \\
(77.3 \%)\end{array}$ & 0.657 \\
\hline $\begin{array}{l}\text { 9.If you feel unwell (eg. feel a little } \\
\text { feverish), you will check your body } \\
\text { temperature with thermometer }\end{array}$ & $\begin{array}{c}137 \\
(61.2 \%)\end{array}$ & $\begin{array}{c}89 \\
(50.9 \%)\end{array}$ & 0.039 & $\begin{array}{c}100 \\
(53.8 \%)\end{array}$ & $\begin{array}{c}126 \\
(59.2 \%)\end{array}$ & 0.278 & $\begin{array}{c}59 \\
(53.2 \%)\end{array}$ & $\begin{array}{c}167 \\
(58.0 \%)\end{array}$ & 0.383 & $\begin{array}{c}168 \\
(54.0 \%)\end{array}$ & $\begin{array}{c}58 \\
(65.9 \%)\end{array}$ & 0.047 & $\begin{array}{c}177 \\
(56.9 \%)\end{array}$ & $\begin{array}{c}49 \\
(55.7 \%)\end{array}$ & 0.837 \\
\hline $\begin{array}{l}\text { 10.Avoid sharing fork and spoon } \\
\text { during eating }\end{array}$ & $\begin{array}{c}186 \\
(83.0 \%) \\
\end{array}$ & $\begin{array}{c}123 \\
(70.3 \%)\end{array}$ & 0.002 & $\begin{array}{c}136 \\
(73.1 \%)\end{array}$ & $\begin{array}{c}173 \\
(81.6 \%)\end{array}$ & 0.053 & $\begin{array}{c}85 \\
(76.6 \%) \\
\end{array}$ & $\begin{array}{c}224 \\
(77.8 \%) \\
\end{array}$ & 0.797 & $\begin{array}{c}238 \\
(76.5 \%)\end{array}$ & $\begin{array}{c}71 \\
(80.7 \%)\end{array}$ & 0.410 & $\begin{array}{c}242 \\
(77.8 \%)\end{array}$ & $\begin{array}{c}67 \\
(76.1 \%) \\
\end{array}$ & 0.740 \\
\hline
\end{tabular}

In terms of attitude, most participants had a neutral attitude toward COVID-19. The level of concern over the COVID-19 situation was also neutral (average score $6.09 \pm 2.32$ out of 10 ) perhaps due to the point in the timeline of COVID-19 at which the observation took place. Indeed, the study was conducted when the COVID-19 situation in Thailand was under control with no local transmission identified, and all the control measures in Thailand had been eased. Interestingly, even though our study participants were international travelers, most of them agreed that traveling abroad should be discouraged during the outbreak. The reason for this finding might be that the COVID-19 situation during the time of data collection was not very active in most countries, and thus some participants tended to be more aware of imported cases.

Regarding prevention practices, the study reported an adequate mean practice score and this score was higher in the group where data were collected during the first period (before the end of the outbreak was declared in Thailand). This finding might be explained by the variation risk perception at that point in time. We hypothesized that when the outbreak was declared to be over, people might reduce their preventive behaviors as a study in Indonesia found that risk perception had a positive influence on preventive behavior [15]. We further analyzed the factor influencing practices. Females tended to have better practices than males; this was consistent with an observation from non-travelers KAP studies [6, 10, 16-18]. As expected, the pretravel advice was found to be associated with a higher practice score toward COVID-19 among travelers; this emphasized the impact of pretravel counseling and advice. Surprisingly, while the education level was significantly associated with the knowledge score, the practice score were similar among those with a low versus high education level. This finding was dissimilar to a Chinese study, which found that the education level was correlated with a good practice [12]. There was also no correlation between the knowledge score versus the practice score, or between the attitude score versus the practice score in our study. Of note, a relatively low percentage of participants reported regular avoidance of public places/use of public transportation, cleaning of high touch surfaces every day, and checking body temperature with a thermometer if feeling unwell, all of which highlighted the need to emphasize on these preventive practices.

\section{Limitations}

The limitations of our study included: i) limited access to travelers due to languages in the questionnaire (English/Thai); ii) a small proportion of non-Thai travelers due to unexpected travel restrictions/lock down during the observation and iii) several potential biases (from the nature of designing a study using an online questionnaire) including voluntary and convenient biases. These may affect the generalization of study results. Furthermore, the study was designed at the beginning of the outbreak, and some important information such as COVID-19 vaccination was not assessed.

\section{Conclusion}

The study was conducted to explore the KAP regarding COVID-19 of travelers, who play a major role in the transmission of COVID-19 and in controlling the pandemic especially as international travel is resuming. This study showed that the majority of travelers had sufficient knowledge, a neutral attitude, and an acceptable 
practicing preventive score toward COVID-19. Social media was the major source of information, suggesting its' significant implication in knowledge, attitude and practice promotion. Furthermore, knowledge about disease transmission should be improved. The factors influencing good practices included pretravel advice, sex, age and the point in the timeline of the outbreak. The lower knowledge and practice score in travelers participating after the end of outbreak was declared, when compared to during lockdown, suggests the importance of intensifying education and strict preventive practices over time. Pretravel counselling and advice should be encouraged in order to improve knowledge, raise awareness and emphasize good preventive measures toward COVID-19 among international travelers for improved pandemic control.

\section{Supplementary Information}

The online version contains supplementary material available at https://doi. org/10.1186/s40794-021-00155-1.

Additional file 1. Site of data collection. A total of 399 international travelers and expatriates were included in the study. One hundred and forty-nine participants (37.3\%) were enrolled from the Hospital for Tropical Diseases while 250 participants (62.7\%) were enrolled from nonhospital areas. Among participants from outside the hospital, 177/250 participants were enrolled from state quarantine or UN soldier line groups (70.8\%), the others (29.2\%) were enrolled from expats groups, or Thai Travel Clinic Facebook page.

Additional file 2. Differences in mean knowledge score between demographic groups. Table shows differences in mean knowledge score between demographic groups.

\section{Acknowledgements}

We would like to thank all travelers participated in the study and the staffs at the Thai Travel Clinic, Hospital for Tropical Diseases, Bangkok, Thailand for their assistance. Thanks to Kollawat Somsri for proofreading the article.

\section{Authors' contributions}

All authors were involved in study design. SP were responsible for data collection. SP, VL, SL and AS were involved in data analysis and interpretation. SP wrote the manuscript. VL, WC, AS, SL, WP, SM, PP and PC provided technical guidance and revised the manuscript. All authors read and approved the final version manuscript.

\section{Funding}

This study was funded by the Faculty of Tropical Medicine, Mahidol University. The funder had no role in the study.

\section{Availability of data and materials}

The datasets supporting the conclusions of this article are included within the article and its additional files. The raw data and the questionnaire used in this study are available at the Faculty of Tropical Medicine, Mahidol University. The corresponding author can be contacted via email: viravarn. luv@mahidol.ac.th

\section{Declarations}

\section{Ethics approval and consent to participate}

This study was approved by the Ethics Committee of the Faculty of Tropica Medicine, Mahidol University (MUTM 2020-029-01). Informed consent was obtained from all participants prior to study enrollment.

\section{Consent for publication}

Not applicable.

\section{Competing interests}

Watcharapong Piyaphanee is an Associate Editor for the journal Tropical Diseases, Travel Medicine and Vaccines. The authors declare that they have no other competing interests.

\section{Author details}

${ }^{1}$ Department of Clinical Tropical Medicine, Faculty of Tropical Medicine, Mahidol University, Bangkok, Thailand. '2Department of Tropical Hygiene, Faculty of Tropical Medicine, Mahidol University, Bangkok, Thailand. ${ }^{3}$ Department of Community Health, Faculty of Public Health, Naresuan University, Phitsanulok, Thailand. ${ }^{4}$ Department of Tropical Pediatrics, Faculty of Tropical Medicine, Mahidol University, Bangkok, Thailand.

Received: 21 May 2021 Accepted: 7 September 2021

Published online: 15 November 2021

\section{References}

1. Pongpirul WA, Mott JA, Woodring JV, Uyeki TM, MacArthur JR, Vachiraphan $A$, et al. Clinical characteristics of patients hospitalized with coronavirus disease. Thailand Emerg Infect Dis. 2020;26(7):1580-5. https://doi.org/10.32 01/eid2607.200598.

2. Pongpirul WA, Pongpirul K, Ratnarathon AC, Prasithsirikul W. Journey of a Thai taxi driver and novel coronavirus. N Engl J Med. 2020;382(11):1067-8. https://doi.org/10.1056/NEJMc2001621.

3. Sirilak S. Thailand's experience in the COVID-19 response: ministry of public health; 2020.

4. Saqlain M, Munir MM, Rehman SU, Gulzar A, Naz S, Ahmed Z, et al. Knowledge, attitude, practice and perceived barriers among healthcare workers regarding COVID-19: a cross-sectional survey from Pakistan. J Hosp Infect. 2020;105(3):419-23. https://doi.org/10.1016/j.jhin.2020.05.007.

5. Clements JM. Knowledge and behaviors toward COVID-19 among US residents during the early days of the pandemic: cross-sectional online questionnaire. JMIR Public Health Surveill. 2020;6(2):e19161. https://doi.org/1 0.2196/19161.

6. Al-Hanawi MK, Angawi K, Alshareef N, Qattan AMN, Helmy HZ, Abudawood Y, et al. Knowledge, attitude and practice toward COVID-19 among the public in the Kingdom of Saudi Arabia: a cross-sectional study. Front Public Health. 2020:8:217. https://doi.org/10.3389/fpubh.2020.00217.

7. Zhang M, Zhou M, Tang F, Wang Y, Nie H, Zhang L, et al. Knowledge, attitude, and practice regarding COVID-19 among healthcare workers in Henan. China J Hosp Infect. 2020;105(2):183. https://doi.org/10.1016/j.jhin.2 020.04.012.

8. Reuben RC, Danladi MMA, Saleh DA, Ejembi PE. Knowledge, attitudes and practices towards COVID-19: an epidemiological survey in north-Central Nigeria. J Community Health. 2020;46(3):457-70. https://doi.org/10.1007/s1 0900-020-00881-1.

9. Srichan P, Apidechkul T, Tamornpark R, Yeemard F, Khunthason S, Kitchanapaiboon S, et al. Knowledge, attitudes and preparedness to respond to COVID-19 among the border population of northern Thailand in the early period of the pandemic: a cross-sectional study. WHO South East Asia J Public Health. 2020;9(2):118-25. https://doi.org/10.4103/2224-3151.2 94305.

10. Salman M, Mustafa ZU, Asif N, Zaidi HA, Hussain K, Shehzadi N, et al. Knowledge, attitude and preventive practices related to COVID-19: a crosssectional study in two Pakistani university populations. Drugs Ther Perspect. 2020;36(7):1-7. https://doi.org/10.1007/s40267-020-00737-7.

11. Yue S, Zhang J, Cao M, Chen B. Knowledge, attitudes and practices of COVID-19 among urban and rural residents in China: a cross-sectional study. J Community Health. 2021;46(2):286-91. https://doi.org/10.1007/s10900-02000877-x.

12. Gao H, Hu R, Yin L, Yuan X, Tang H, Luo L, et al. Knowledge, attitudes and practices of the Chinese public with respect to coronavirus disease (COVID19): an online cross-sectional survey. BMC Public Health. 2020;20(1):1816. https://doi.org/10.1186/s12889-020-09961-2.

13. Ladiwala ZFR, Dhillon RA, Zahid I, Irfan O, Khan MS, Awan S, et al. Knowledge, attitude and perception of Pakistanis towards COVID-19; a large cross-sectional survey. BMC Public Health. 2021;21(1):21. https://doi.org/1 0.1186/s12889-020-10083-y 
14. Hatabu A, Mao X, Zhou Y, Kawashita N, Wen Z, Ueda M, et al. Knowledge, attitudes, and practices toward COVID-19 among university students in Japan and associated factors: an online cross-sectional survey. PLoS One. 2020;15(12):e0244350. https://doi.org/10.1371/journal.pone.0244350.

15. Fenitra RM, Praptapa A, Suyono E, Kusuma PDI, Usman I. Factors influencing preventive intention behavior towards COVID-19 in Indonesia. The Journal of Behavioral Science. 2021;16(1):14.

16. Azlan AA, Hamzah MR, Sern TJ, Ayub SH, Mohamad E. Public knowledge, attitudes and practices towards COVID-19: a cross-sectional study in Malaysia. PLoS One. 2020;15(5):e0233668. https://doi.org/10.1371/journal. pone.0233668

17. Bazaid AS, Aldarhami A, Binsaleh NK, Sherwani S, Althomali OW. Knowledge and practice of personal protective measures during the COVID-19 pandemic: a cross-sectional study in Saudi Arabia. PLoS One. 2020;15(12): e0243695. https://doi.org/10.1371/journal.pone.0243695.

18. Olaimat AN, Aolymat I, Elsahoryi N, Shahbaz HM, Holley RA. Attitudes, anxiety, and behavioral practices regarding COVID-19 among university students in Jordan: a cross-sectional study. Am J Trop Med Hyg. 2020;103(3): 1177-83. https://doi.org/10.4269/ajtmh.20-0418.

\section{Publisher's Note}

Springer Nature remains neutral with regard to jurisdictional claims in published maps and institutional affiliations.

Ready to submit your research? Choose BMC and benefit from:

- fast, convenient online submission

- thorough peer review by experienced researchers in your field

- rapid publication on acceptance

- support for research data, including large and complex data types

- gold Open Access which fosters wider collaboration and increased citations

- maximum visibility for your research: over $100 \mathrm{M}$ website views per year

At $\mathrm{BMC}$, research is always in progress.

Learn more biomedcentral.com/submissions 